\title{
Model Experimental Study on Stress Transfer and Redistribution in a Clay Landslide under Surcharge Load
}

\author{
Heng-Jun Hou $\mathbb{D}$,,$^{1,2}$ Bo Wang $\mathbb{D}^{1,2}$ Quan-Xiang Deng, ${ }^{1,2}$ Zheng-Wei Zhu $\mathbb{D}^{1,2}$ and Feng Xiao $^{1,2,3}$ \\ ${ }^{1}$ School of Civil Engineering of Chongqing University, Chongqing 400045, China \\ ${ }^{2}$ Key Laboratory of New Technology for Construction of Cities in Mountain Area (Chongqing University), Ministry of Education, \\ Chongqing 400045, China \\ ${ }^{3}$ CCTEG Chongqing Engineering Co., Ltd., Chongqing 400016, China
}

Correspondence should be addressed to Zheng-Wei Zhu; zqiao99@126.com

Received 2 April 2020; Accepted 24 August 2020; Published 11 December 2020

Academic Editor: Ivan Gutierrez-Urrutia

Copyright (c) 2020 Heng-Jun Hou et al. This is an open access article distributed under the Creative Commons Attribution License, which permits unrestricted use, distribution, and reproduction in any medium, provided the original work is properly cited.

\begin{abstract}
Stress transfer and redistribution always accompany with the evolution of landslides. However, previous literature studies have mainly focused on stages of stress variation, and far too little attention has been paid to detailed transfer and redistribution process analysis on stress variation. In this paper, a large-scale clay model slope with masonry slide bed and prefabricated cambered slip surface was constructed. Earth pressure cells were embedded into slip mass to monitor vertical and horizontal stresses in different parts of the test soils under the set load sequence. Stress transfer efficiency (STE) indicators based on qualified stress monitoring datasets (tested by Shapiro-Wilk method) were established to quantify the stress transfer process. Staged development of stress inside the clay slope was analyzed through extracting slopes of stress curves and limit loads. The stress redistribution process was analyzed using STE and deflection of stress isolines derived from numerical simulation. Moreover, to study the influence of loading position on stress variation, geometry partitioning has also been discussed. Results showed that vertical and horizontal stresses had different growth trends on both sides of $80 \mathrm{kN}$ and $60 \mathrm{kN}$, respectively. Horizontal stress growth has two stages; vertical stress growth has two stages in soils close to slope surface and shear outlet, while there are three stages in other soils. Vertical stress transfer efficiency (VSTE) and horizontal stress transfer efficiency (HSTE) are recommended to quantify stress transfer and redistribution process. Based on VSTEs and HSTEs, the slip mass could be partitioned into three parts: loading zone, transfer zone, and free zone. Deflecting amplitudes of stress isolines were in consistency with the results revealed by STEs.
\end{abstract}

\section{Introduction}

Most cities are located on slopes with gradients of $35 \%$ or more [1]. The construction of buildings and infrastructures, etc. changes the stress field of slope. Landslide disasters caused by the change of stress field occur from time to time, which seriously threaten the construction safety and cause the project delay and the increase of additional investment. The change of stress field implies the transfer and redistribution of stress. A better understanding of stress transfer and redistribution process is of wide-ranging importance for engineers to carry out reliable design $[2,3]$.

Stress transfer phenomena have been widely reported in tectonophysics [4-6], interaction between rock and soil masses and structures [7, 8], etc. Literatures [9-12] revealed a strong association between stress variation and slope failure. However, stress variation in current researches is mainly associated with the stages of landslide evolution process and detailed process analysis on stress variation has hitherto received scant attention by scholars.

Quantifying stress transfer, including stress redistribution during stress transfer process, is an important aspect of stress variation process analysis. Lamandé and Schjønning [13] and Schjønning et al. [14] employed parameters $\alpha$ and $\beta$ to describe vertical stress redistribution in three dimensions under wheel load. Nevertheless, this analytical solution is based on the assumptions of semi-infinite body and superelliptic form of stress distribution, and the analytical 
TABLE 1: Physical and mechanical parameters of the model test materials.

\begin{tabular}{lccccc}
\hline Name & $\begin{array}{c}\text { Unit weight } \\
\left(\mathrm{kN} / \mathrm{m}^{3}\right)\end{array}$ & $\begin{array}{c}\text { Cohesion } \\
(\mathrm{kPa})\end{array}$ & $\begin{array}{c}\text { Friction angle } \\
\left({ }^{\circ}\right)\end{array}$ & $\begin{array}{c}\text { Young's modulus } \\
(\mathrm{MPa})\end{array}$ & $\begin{array}{c}\text { Poisson's ratio } \\
\text { Slide bed }\end{array}$ \\
\hline & 24.5 & 3470 & 14.4 & $2.1 \times 10^{4}$ & 0.15 \\
Soils & 19.4 & 15.0 & 22.0 & 2.5 & 0.35 \\
\hline
\end{tabular}

solution under these assumptions seems not appropriate for shallow landslides with diverse soil-rock interfaces. Liu and Wu [15] proposed Lowe-Karafiath method (1960) to depict directions and magnitudes of stress transfer, but the method falls under the category of limit equilibrium theory and could not reflect progressive failure of landslides. $\mathrm{Ng}$ et al. [16] employed the ratio of horizontal stress to vertical stress in the same monitoring point to research stress increase. Despite ignoring the ubiquitous issue of principal stress rotation in geotechnical engineering [17-19] and stress ratio in the same monitoring point could not describe stress transfer and redistribution, the stress ratio method provides guidance to research stress variation. Xiong et al. [20] employed the increment of Coulomb failure stress to study stress transfer. But, as a commonly used stress monitoring equipment in in situ surveys and model tests, earth pressure cell (EPC) is difficult to obtain shear stress. In short, the developing laws of stress transfer and redistribution inside slopes are still unclear and that warrants further study.

Field surveying and monitoring, model experiments, and numerical simulation are three main methods adopted for landslide research. Comparatively, field surveys, though accurate, would be restricted by many uncontrollable factors and are time-consuming. Model test is one of the most effective and acceptable methods for studying landslides [21]. Numerical simulation is an effective supplement to model test, which can not only overcome the defects of artificial uncertainties during the course of experiment but also contribute to reflecting regular results.

In this paper, laboratory tests were carried out in a largescale clay slope with a circular arc shape slip surface. The primary objective of this paper is to put forward reasonable and workable indicators of quantifying stress transfer and redistribution based on stress monitoring data gathered by EPCs. Meanwhile, numerical simulation validates the correctness of the proposed indicators. It is inconvenient to embed EPCs in masonry slide bed; study on stress variation process is only limited to slip mass of clay landslide.

\section{Model Test}

2.1. Model Box and Materials. The whole model test box was soldered with thick square steel pipes and rectangular steel pipes, and the net length, width, and height were $4.5 \mathrm{~m}, 2 \mathrm{~m}$, and $1.6 \mathrm{~m}$, respectively. The side walls of the test chamber were surrounded by $8+8 \mathrm{~mm}$ double-layer tempered glass. In order to ensure practicability and safety during the experiment, the upper part of the model box was equipped with a $1 \mathrm{~m}$ high guardrail.

Vertical and horizontal stresses in slip mass are the research objects of this experiment, and little attention is paid to nonsliding part (slide bed). Given that a circular arc shape slip surface is universal in clay slope, the slide bed and slip mass are separated by a cambered interface in model test. The slide bed was constructed of MU20 shale bricks and M5 cement mortar with a ratio of $1: 1$ (cement to sand). Physical and mechanical parameters of the model test materials are listed in Table 1.

2.2. Construction of Model Slope and Loading Method. Size, loading position, and monitoring plane of the model slope are shown in Figure 1. The top surface of the slide bed was $0.3 \mathrm{~m}$ long; the length, width, and height of the bottom surface were $4.5 \mathrm{~m}, 2 \mathrm{~m}$, and $1.6 \mathrm{~m}$, respectively, wherein the slide bed at the slope toe was $0.5 \mathrm{~m}$ long and the height was $0.3 \mathrm{~m}$. The radius of the prefabricated cambered surface was about $3.7 \mathrm{~m}$. Due to the large thickness of soils, a layer of $1.5 \mathrm{~mm}$-thick stainless-steel plate was paved on the interface to ensure the soils slide finally. Nonthixotropic natural clay (derived from Chongqing and regardless of soil texture) containing very little sand and organic matter was used to construct soil slope by layered filling method above the interface, and each layer was $20 \mathrm{~cm}$. To reduce friction, a film of petroleum lubricant between the test soils and the side walls of model box was applied. After that, the slope was cut down from the shoulder to the toe with a gradient of $60^{\circ}$.

The loading sequence applied to the test was $5 \mathrm{kN}, 10 \mathrm{kN}$, $20 \mathrm{kN}, 30 \mathrm{kN}, 40 \mathrm{kN}, 60 \mathrm{kN}, 80 \mathrm{kN}, 100 \mathrm{kN}, 120 \mathrm{kN}$, and $140 \mathrm{kN}$. In order to ensure uniform load transferred to the soil mass, the bearing plate $(193 \times 100 \times 1 \mathrm{~cm})$ was placed on the slope crest prior to the test. The first two stages of loads were achieved by placing the stack blocks $(\mathrm{C} 40,52 \times 50 \times 20 \mathrm{~cm})$ on the bearing plate. When the loads were not less than $20 \mathrm{kN}$, the grilled steel frame was placed on the stack blocks, and the loads were applied step by step on the top of the soil slope via three hydraulic jacks (the simultaneous loading was realized by a three-piece joint) fixed on the reaction frame. The detailed loading scheme is presented in Zhu et al.'s work [22]. The test loading system is shown in Figure 2.

During constructing soil slope, EPCs (Longyu Civil Engineering Instruments Factory, Danyang, Jiangsu, China) were embedded into soils. The two EPCs were installed perpendicular to each other at each measuring point so that the vertical one measures total horizontal stress, while the horizontal one measures total vertical stress. As shown in Figure 3, in order to describe the effect of loading position on stress variation in this paper, the test soils were divided into three parts, that is, loading zone, transfer zone, and free zone, while a total of 21 stress monitoring points were arranged in these three parts. The serial numbers of EPCs are 1-1, 1-2, 1-3, 2-1, 2-2, 3-1, and 3-2 in the loading zone, 1-4, 1-5, 2-3, 2-4, 3-3, 3-4, 4-1, 4-2, and 5-1 in the transfer zone, and 2-5, 3-5, 4-3, 4-4, and 5-2 


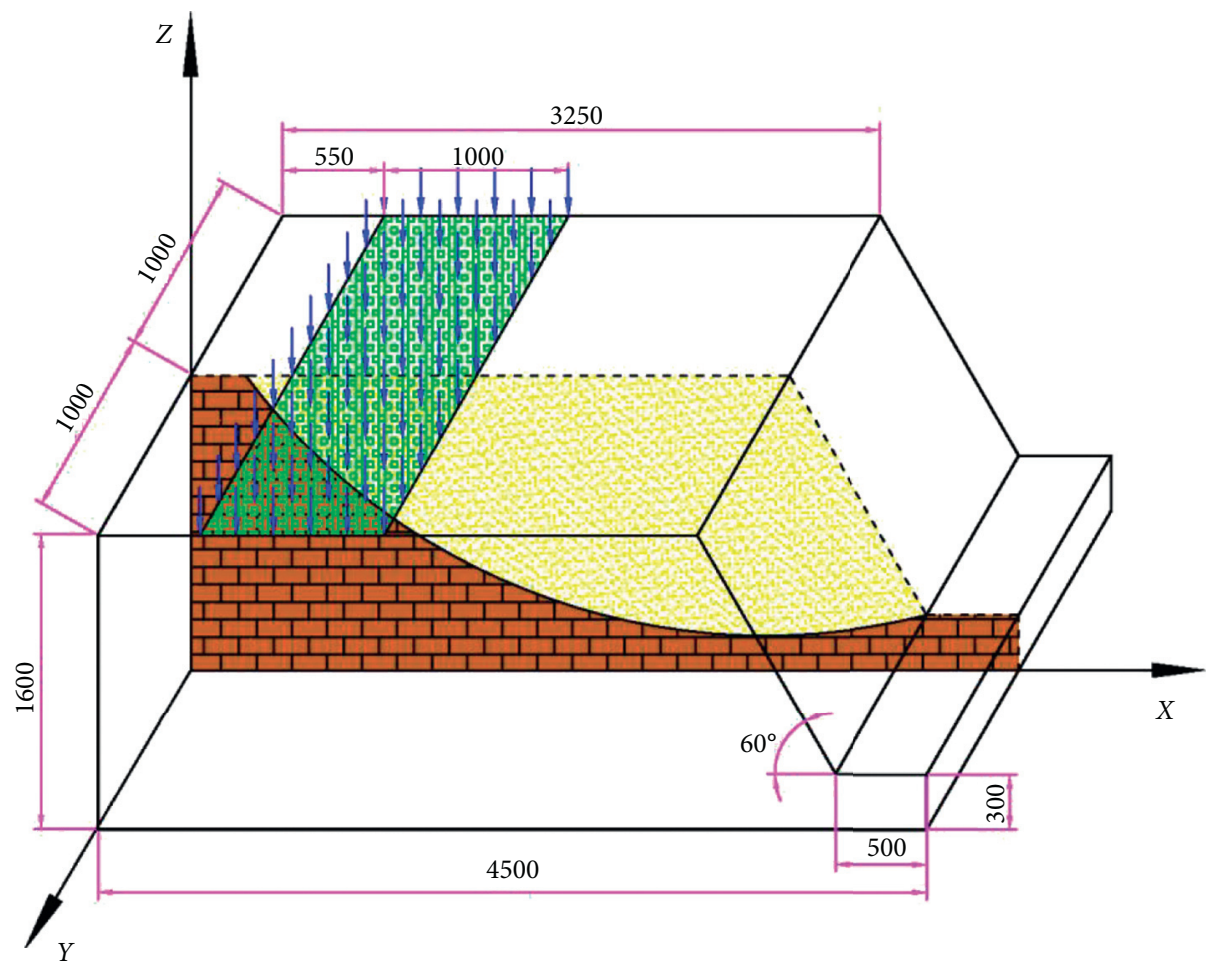

FIGURE 1: Configuration, loading position, and monitoring plane of the model slope (unit: $\mathrm{mm}$ ). The model slope lies above the horizontal plane $x y$ with $z$ being a vertical coordinate, directed upward.

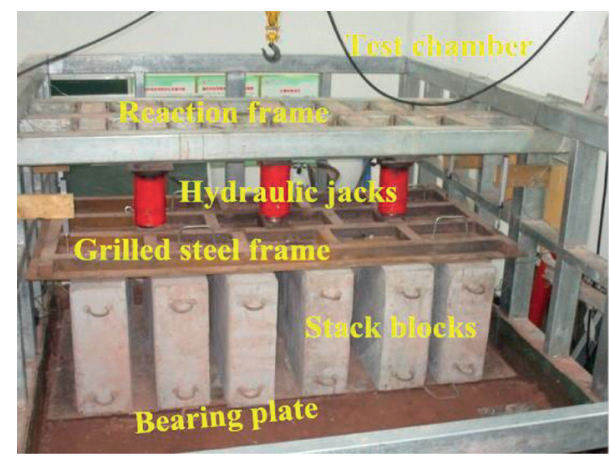

FIGURE 2: Loading system.

in the free zone. The division of these three parts is based on the stress transfer efficiency, the definition of which is in Section 3. The geometry partitioning of these three parts will be discussed in Section 5.3.

\section{Analytical Method}

In this paper, differential curves of stresses were used to describe stress increase degree at specific monitoring points. Moreover, "benchmark value" was used to describe the variation amplitude of stress growth in the analysis of slopes of stress curves. It means the sum of the interval differences of decline rates and growth rates. Referring to the aforementioned stress ratio method, "stress transfer efficiency (STE)" will be used as an indicator to describe stress transfer between adjacent measuring points, as shown in equations (1) and (2). VSTE stands for vertical stress transfer efficiency in equation (1), and HSTE stands for horizontal stress transfer efficiency in equation (2).

$$
\begin{aligned}
& \text { VSTE }=\left[\frac{(\text { max value }- \text { min value })_{\text {lower }}}{(\text { max value }- \text { min value })_{\text {upper }}}\right] \times 100 \%, \\
& \text { HSTE }=\left[\frac{(\text { max value }- \text { min value })_{\text {right }}}{(\text { max value }- \text { min value })_{\text {left }}}\right] \times 100 \% .
\end{aligned}
$$

Dynamic process of stress redistribution was characterized by stress isolines derived from the commercial program SIGMA/W (GEOSLOPE International, Calgary, Canada) through load-deformation mode. Calculation model, including boundary conditions, is shown in Figure 4. The numerical simulation parameters are shown in Table 1. Variations of vertical stresses are notable under normal loads. The premises on vertical stress isolines, meanwhile, were introduced: vertical stresses of the measuring points at the same elevation were approximately located on the same horizontal isoline, when relatively smaller loads were applied; then the isolines gradually deflected during the loading process and the isolines changed continuously between adjacent soil units.

Reliability is a basic precondition for data analysis. Beer et al. [23] pointed out that when boundary condition information was available only, nonprobabilistic methods, such as interval analysis or fuzzy modeling, had great advantages. In this paper, Shapiro-Wilk method (W test), one of the interval analysis methods, was employed to test the reliability of monitored datasets. When the confidence level 


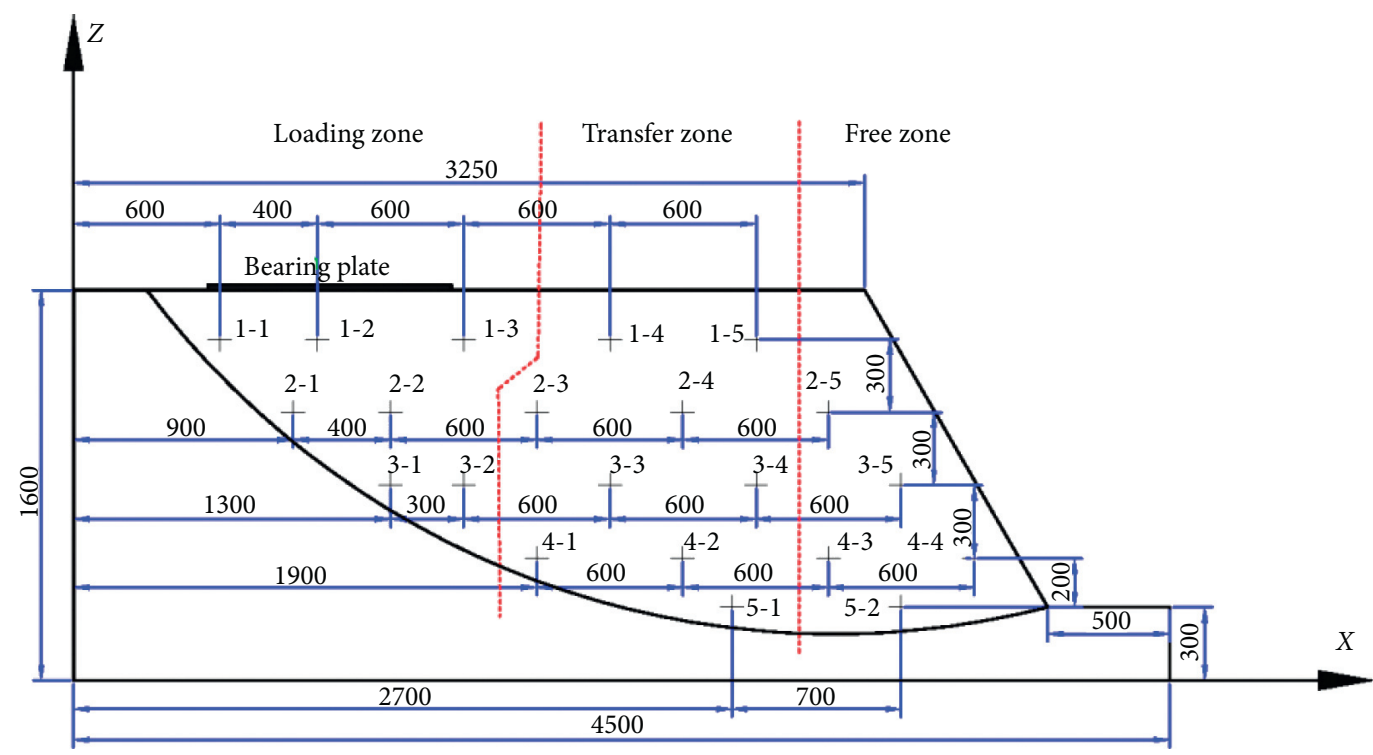

Figure 3: Plane layout of Earth pressure cells (unit: mm).

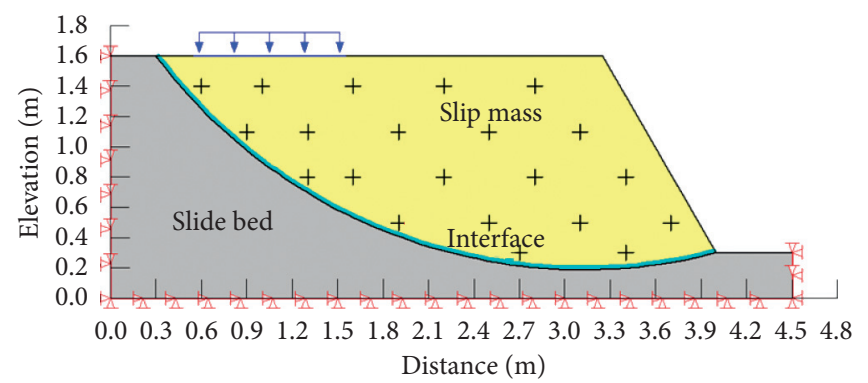

Figure 4: Numerical calculation model.

during the test was 0.05 and the $P$ value was less than 0.05 , the corresponding dataset was rejected and not discussed.

\section{Results}

With a load of $40 \mathrm{kN}$, a vertical crack appeared on the soil mass between the loading position and the trailing edge of the slope. Crack continued to develop when loading resumed. When it was at $140 \mathrm{kN}$, soil slope failure occurred. At this time, jacks were difficult to maintain a stable load state, and the test ended.

Qualified datasets were plotted in the semilogarithmic coordinate system of the load. Tables 2-4 show that the vertical and horizontal stresses at qualified measuring points could be fitted into power functions of three parameters shaped like $y=a+b\left(x^{k}-1\right) / k(a, b$, and $k$ were fitting constants) with high fitting precisions. In addition, the horizontal and vertical stress values at each measuring point obtained by the numerical simulation results were in good agreement with the measured stress values in the model test, and the maximum error did not exceed $7.15 \%$. The numerical simulation results were credible.

4.1. Stress Variations in the Loading Zone. Table 2 shows the reliability results of measured stresses in the loading zone.
From Figure 5(a), we have the following: (1) In combination with the standard deviation in Table 2, it can be seen that measuring points closer to the bearing plate were liable to be affected by soil compression, and the amplitude of stress variation was greater, comparing the measuring points 1-2 and 2-1,2-2 and 3-1, and 1-3 and 3-2. The vertical stresses at different depths tended to be the same at approximately the same horizontal coordinates; namely, the initial horizontal isoline had a serious deflection, and more and more tended to be vertical. (2) According to equation (1), VSTEs from $1-2$ to $2-1$, from $2-2$ to $3-1$, and from $1-3$ to $3-2$ were $89.93 \%, 80.19 \%$, and $71.65 \%$, respectively. This showed that VSTEs decreased with increasing depths.

From Figure 5(b), we have the following: (1) In combination with the standard deviation in Table 2 , it can be seen that the closer to the bearing plate, the greater variations of the horizontal stresses, from comparison of the measuring points 1-2 and 2-1 and 1-3 and 3-2 at approximately the same horizontal coordinates. (2) Results with equation (2) showed that HSTEs of measuring points from 1-2 to 1-3 and from $2-1$ to $2-2$ were, respectively, $72.34 \%$ and $60.14 \%$. That is, HSTEs in the loading zone decreased gradually with increasing depths.

Considering the stress concentration effect at the ends of the bearing plate and the influence of the slip surface, as a 
TABLE 2: Reliability verification of measured stresses in the loading zone.

\begin{tabular}{|c|c|c|c|c|c|c|c|c|c|}
\hline Stress type & No. of EPCs & W statistic & $P$ value & Accept/reject $(\mathrm{A} / \mathrm{R}) \mathrm{W}$ test & Std. dev. & Minimum & Mean & Maximum & $\begin{array}{c}\text { Fitting } \\
\text { precision }\end{array}$ \\
\hline \multirow{7}{*}{ Vertical } & $1-1$ & 0.9193 & 0.3124 & $\mathrm{~A}$ & 11.713 & 4.96 & 17.00 & 35.10 & 0.9999 \\
\hline & $1-2$ & 0.9204 & 0.3217 & $\mathrm{~A}$ & 26.052 & 5.79 & 33.34 & 72.61 & 0.9999 \\
\hline & $1-3$ & 0.9206 & 0.3236 & $\mathrm{~A}$ & 13.889 & 5.87 & 20.43 & 41.49 & 0.9999 \\
\hline & $2-1$ & 0.9166 & 0.2913 & A & 22.825 & 12.00 & 36.49 & 72.09 & 0.9997 \\
\hline & $2-2$ & 0.9172 & 0.2958 & A & 20.459 & 11.50 & 33.44 & 64.87 & 0.9992 \\
\hline & $3-1$ & 0.9131 & 0.2655 & $\mathrm{~A}$ & 16.539 & 18.00 & 35.50 & 60.80 & 0.9992 \\
\hline & $3-2$ & 0.8984 & 0.1766 & $\mathrm{~A}$ & 10.016 & 16.00 & 27.30 & 41.52 & 0.9935 \\
\hline \multirow{7}{*}{ Horizontal } & $1-1$ & 0.8056 & 0.0112 & $\mathbf{R}$ & 4.859 & -2.89 & 0.43 & 9.14 & 0.9882 \\
\hline & $1-2$ & 0.9131 & 0.2654 & A & 7.872 & -0.91 & 6.78 & 19.59 & 0.9982 \\
\hline & $1-3$ & 0.9240 & 0.3534 & A & 5.740 & 1.10 & 7.02 & 15.93 & 0.9993 \\
\hline & $2-1$ & 0.8597 & 0.0571 & $\mathrm{~A}$ & 5.119 & 1.64 & 5.58 & 14.46 & 0.9902 \\
\hline & $2-2$ & 0.9202 & 0.3204 & A & 3.031 & 2.32 & 5.20 & 10.03 & 0.9943 \\
\hline & $3-1$ & 0.6410 & $8.2933 \mathrm{E}-5$ & $\mathbf{R}$ & 1.352 & 4.84 & 5.35 & 7.59 & 0.9793 \\
\hline & $3-2$ & 0.9095 & 0.2404 & A & 1.693 & 5.30 & 6.79 & 9.46 & 0.9850 \\
\hline
\end{tabular}

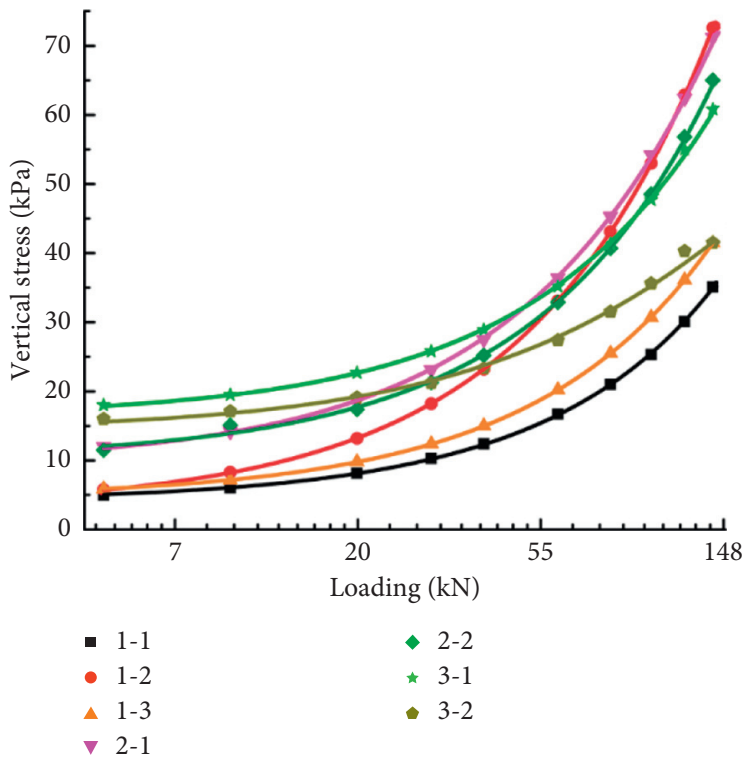

(a)

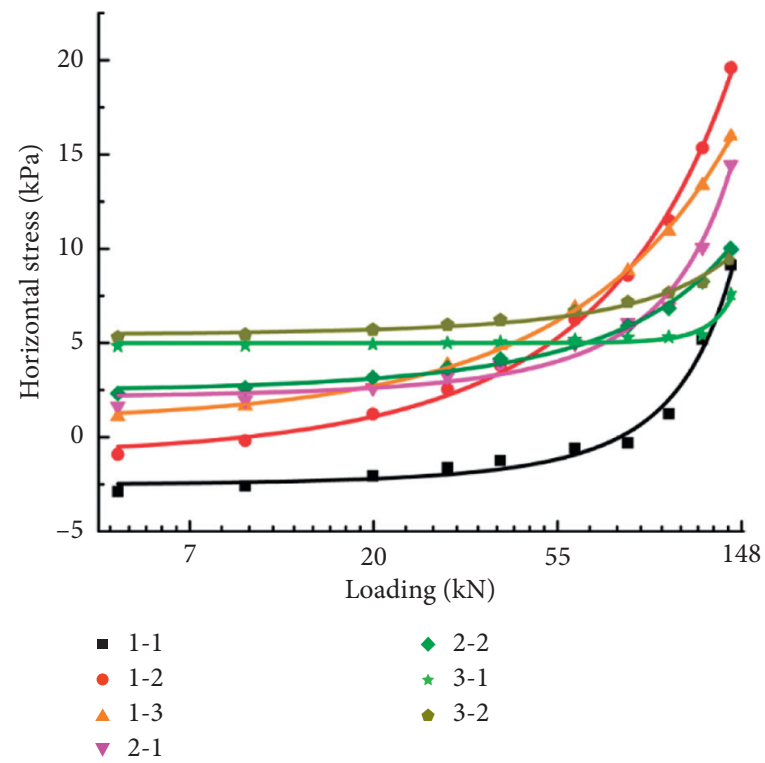

(b)

Figure 5: Relationship between the qualified stresses and loading in the loading zone. (a) Vertical stress. (b) Horizontal stress.

generality, the measuring points $1-2,2-2$, and $3-2$ were picked as the research objects. At the beginning of the test, the loads were mainly used for compacting soil skeleton, so the slopes of the stress curves decreased.

In Figure 6(a), with $80 \mathrm{kN}$ as the limit load, the slopes of the vertical stress curves decreased at the initial loading stages and then became stable and then decreased as a whole after $80 \mathrm{kN}$.

In Figure 6(b), with $60 \mathrm{kN}$ as the limit load, the slopes of horizontal stress curves firstly decreased and then showed a sharp rise; before $60 \mathrm{kN}$, the range of decline rate of measuring points $1-2,2-2$, and 3-2 accounted for $24.85 \%$, $15.74 \%$, and $7.20 \%$ of the respective benchmark value; after $60 \mathrm{kN}$, the range of growth rate, respectively, accounted for $75.15 \%, 84.26 \%$, and $92.80 \%$ of the benchmark value. The influence of loading on the horizontal stress growth gradually decreased in the depth direction before the limit load, and the law was opposite after the limit load.
4.2. Stress Variations in the Transfer Zone. Table 3 shows the reliability results of measured stresses in the transfer zone.

From Figure 7(a), we have the following: (1) Combined with the standard deviations in Tables 2 and 3, it can be seen that the variation amplitude of vertical stresses in the transfer zone was smaller than that in the loading zone. (2) Comparing the vertical stresses of the same horizontal coordinate in the transfer zone and combining with the standard deviation in Table 3, the closer to the loading zone, the greater variation amplitude of the stresses at the measuring points. (3) Comparing the measuring points $2-3$ and $4-1,2-4$ and $4-2,1-4$ and 3-3, and 1-5 and 3-4, it was found that the final stress differences were large at approximately the same horizontal coordinates. (4) From equation (1), VSTEs from point 2-3 to 4-1, from 2-4 to 4-2, from 1-4 to 3-3, and from 1-5 to 34 were $160.12 \%, 249.22 \%, 886.44 \%$, and $906.78 \%$, 


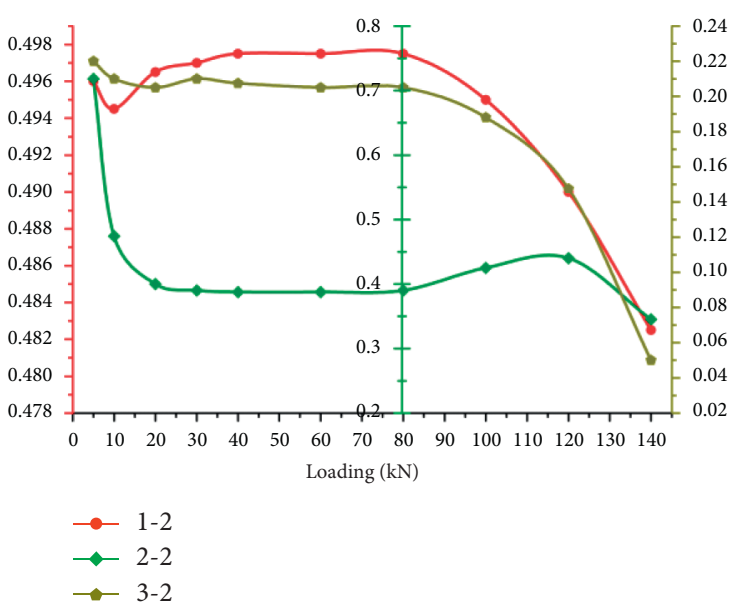

(a)

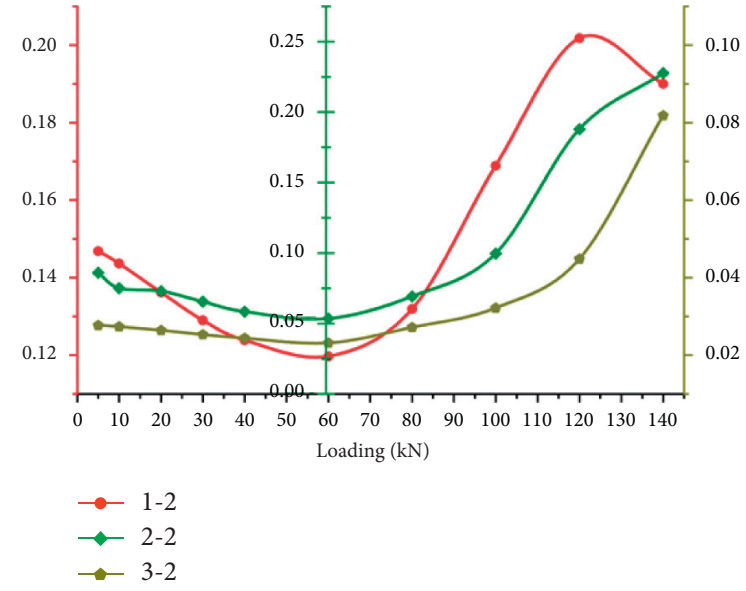

(b)

Figure 6: Slopes of stress curves in the loading zone (take monitoring points 1-2, 2-2, and 3-2 as an example). (a) Vertical and (b) horizontal.

TABLE 3: Reliability verification of measured stresses in the transfer zone.

\begin{tabular}{cccccccccc}
\hline Stress type & No. of EPCs & W statistic & $P$ value & Accept/reject (A/R) W test & Std. dev. & Minimum & Mean & Maximum & $\begin{array}{c}\text { Fitting } \\
\text { precision }\end{array}$ \\
\hline & $1-4$ & 0.9028 & 0.2001 & A & 0.239 & 3.19 & 3.42 & 3.78 & 0.9986 \\
& $1-5$ & 0.8739 & 0.0870 & $\mathrm{~A}$ & 0.220 & 3.14 & 3.32 & 3.73 & 0.9625 \\
& $2-3$ & 0.9166 & 0.2915 & $\mathrm{~A}$ & 3.794 & 8.82 & 12.87 & 18.80 & 0.9992 \\
Vertical & $2-4$ & 0.8995 & 0.1824 & $\mathrm{~A}$ & 0.508 & 5.62 & 6.15 & 6.90 & 0.9959 \\
& $3-3$ & 0.9204 & 0.3216 & $\mathrm{~A}$ & 2.646 & 13.50 & 16.30 & 18.73 & 0.9996 \\
& $3-4$ & 0.9107 & 0.2486 & $\mathrm{~A}$ & 2.039 & 8.95 & 11.02 & 14.30 & 0.9989 \\
& $4-1$ & 0.9163 & 0.2889 & $\mathrm{~A}$ & 6.146 & 20.40 & 26.38 & 36.38 & 0.9974 \\
& $4-2$ & 0.9237 & 0.3511 & $\mathrm{~A}$ & 1.237 & 21.26 & 22.52 & 24.45 & 0.9991 \\
& $5-1$ & 0.9124 & 0.2604 & $\mathrm{~A}$ & 3.160 & 15.40 & 18.47 & 23.60 & 0.9987 \\
\hline & $1-4$ & 0.9243 & 0.3564 & $\mathrm{~A}$ & 1.062 & 2.04 & 3.11 & 4.78 & 0.9977 \\
Horizontal & $1-5$ & 0.9248 & 0.3609 & $\mathrm{~A}$ & 0.356 & 2.27 & 2.62 & 3.19 & 0.9963 \\
& $2-3$ & 0.9273 & 0.3841 & $\mathrm{~A}$ & 3.788 & 3.51 & 7.36 & 13.26 & 0.9981 \\
& $2-4$ & 0.9283 & 0.3938 & $\mathrm{~A}$ & 1.454 & 3.43 & 4.92 & 7.18 & 0.9982 \\
& $3-3$ & 0.9275 & 0.3859 & $\mathrm{~A}$ & 2.160 & 5.44 & 7.64 & 10.98 & 0.9983 \\
& $3-4$ & 0.9276 & 0.3871 & $\mathrm{~A}$ & 1.074 & 4.68 & 5.78 & 7.45 & 0.9985 \\
& $\mathbf{4}-1$ & $\mathbf{0 . 7 4 2 9}$ & $\mathbf{0 . 0 0 1 7}$ & $\mathrm{R}$ & $\mathbf{0 . 0 7 4}$ & $\mathbf{7 . 5 2}$ & $\mathbf{7 . 7 2}$ & $\mathbf{7 . 7 6}$ & $\mathbf{0 . 9 6 7 8}$ \\
& $4-2$ & 0.9256 & 0.3676 & $\mathrm{~A}$ & 0.870 & 7.50 & 8.38 & 9.73 & 0.9990 \\
& $5-1$ & 0.9233 & 0.3466 & $\mathrm{~A}$ & 0.287 & 9.37 & 9.66 & 10.11 & 0.9992 \\
\hline
\end{tabular}

respectively. The above-mentioned VSTEs were greater than or even far greater than $100 \%$, which indicated that the changes of the vertical stresses in the transfer zone were affected by the stress redistribution from the loading zone.

The effect of stress redistribution could be characterized by the deflection of stress isolines. (1) Firstly, the transfer processes from 1-4 to 3-3 and from 1-5 to 3-4 were compared. VSTEs of both groups were much higher than $100 \%$, and the latter was higher than the former. According to the premises on vertical stress isolines, during the loading process, the more deflecting of the isolines (near the loading zone) to the slip surface, the lower the corresponding VSTEs. (2) Following the variation rule of the isolines above, the deflection of the isoline from 2-3 to 4-1 to the slip surface was greater and accordingly the VSTE was lower, compared with those from 2-4 to 4-2.
From Figure 7(b), we have the following: (1) Combined with the standard deviation in Table 3, the closer to the loading zone, the greater variations of the horizontal stresses. (2) From equation (2), HSTEs from points 1-4 to 1-5, from 2-3 to $2-4$, and from $3-3$ to $3-4$ were $33.58 \%, 38.46 \%$, and $50.00 \%$, respectively. This demonstrated that the horizontal stresses in the transfer zone increased gradually with depth. (3) HSTEs in the transfer zone were lower than those in the loading zone.

The slopes of stress curves of measuring points 1-4, 2-4, 3-3, and 4-2 were representative in the transfer zone.

In Figure 8(a), (1) At $80 \mathrm{kN}$, the changes of slopes of vertical stress curves on both sides were opposite, and $80 \mathrm{kN}$ could still be regarded as the limit load. (2) Under the same horizontal coordinates, the changes of the slopes of the vertical stress curves at lower depths were smaller (by an order of magnitude) than those at deeper depths. This revealed that the vertical stresses of the measuring points 


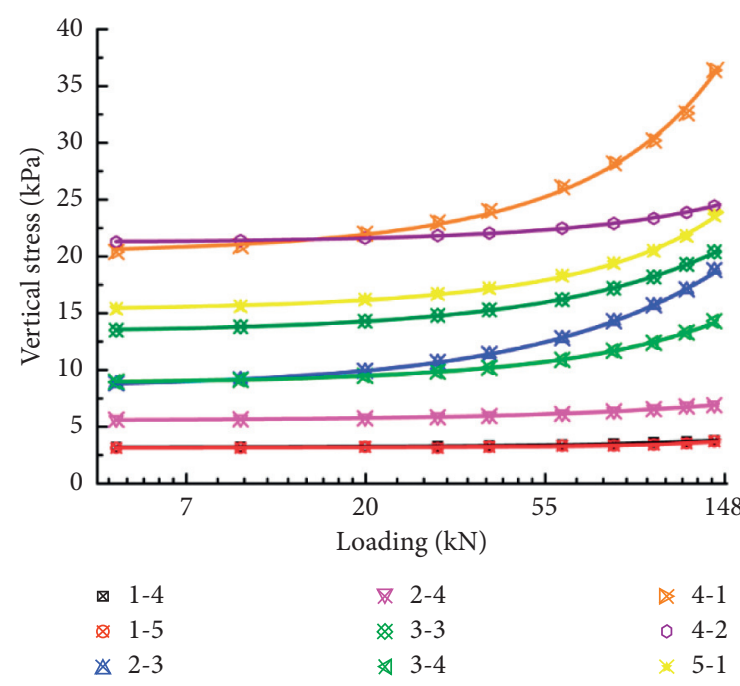

(a)

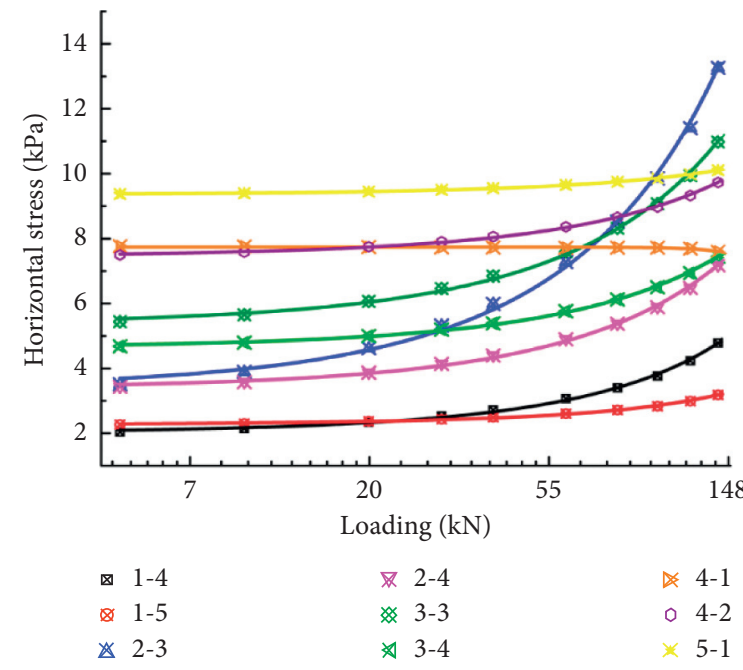

(b)

Figure 7: Relationship between the qualified stresses and loading in the transfer zone. (a) Vertical stress. (b) Horizontal stress.

with larger depths were more susceptible to stress transfer. As for the curves of 1-4 and 3-3 and 2-4 and 4-2, the change trends were opposite, which needs further study.

From Figure 8(b), we have the following: With $60 \mathrm{kN}$ as the limit load, the slopes of horizontal stress curves decreased first and then showed a rapid rising trend; before $60 \mathrm{kN}$, the range of decline rate of measuring points 1-4, 2-4, $3-3$, and $4-2$ accounted for $24.06 \%, 27.15 \%, 21.30 \%$, and $20.42 \%$ of the respective benchmark value, and, after $60 \mathrm{kN}$, the range of growth rate, respectively, accounted for $75.94 \%$, $72.85 \%, 78.70 \%$, and $79.58 \%$ of the benchmark value. The effect of loading on the horizontal stresses decreased with depth on the whole before the limit load, but this trend was not obvious compared with that in the loading zone. After the limit load, the law was opposite, and the growth trend was not remarkable.

4.3. Stress Variations in the Free Zone. Table 4 shows the reliability results of measured stresses in the free zone.

From Figure 9, we have the following: (1) According to the standard deviation in Table 4, stress variations in the free zone were very small. (2) The vertical stresses in the free zone were affected by the stress redistribution from the transfer zone. From equation (1), VSTEs from measuring points 2-5 to $4-3$ and from $3-5$ to $5-2$ were $594.44 \%$ and $176.83 \%$, respectively. By means of the measuring point 3-4, and from equation (2), HSTEs from the measuring points 3-4 to 3-5 and from $4-3$ to $4-4$ were $41.88 \%$ and $66.27 \%$, respectively. This meant that HSTEs in the free zone increased gradually with increasing depths.

The slope of stress curve at each measuring point in the free zone was similar, and the measuring points 2-5 and 4-3 were taken for analysis. Before $80 \mathrm{kN}$, the soil skeleton in the free zone was gradually compacted due to slope cutting, and the slopes of vertical stress curves decreased. The whole soil slope slid at the last load and the experiment ended, so the slopes of the vertical stress curves did not show a downward trend after $140 \mathrm{kN}$.

From Figure 10, we have the following: (1) The limit loads for the slopes of vertical and horizontal stress curves were $80 \mathrm{kN}$ and $60 \mathrm{kN}$, respectively. (2) Before $60 \mathrm{kN}$, the range of decline rate at measuring points $2-5$ and 4-3 accounted for $24.75 \%$ and $24.48 \%$ of the respective benchmark value. After $60 \mathrm{kN}$, the range of growth rate, respectively, accounted for $75.25 \%$ and $75.52 \%$ of the benchmark value. Before the limit load, the effect of loading on the horizontal stresses showed an insignificant decreasing trend with depth. After the limit load, a nondistinctive growth trend was shown.

\section{Discussion}

5.1. Experimental Model. The large-scale model test is costly to perform but is useful in meeting special needs required for the verification of earth pressures and the validation of numerical model. However, it is difficult to ensure remoulded clay slope slide along circular arc shape slip surface under laboratory conditions. Meanwhile, the amount of clay soils is relatively large (about 14 tons) in this large-scale model test. For these reasons, a prefabricated cambered surface was constructed. As for masonry slide bed, it is the focus of this paper to study vertical and horizontal stress variations of slip mass in clay slope, and less attention is paid to nonsliding part. The occurrence of landslide along prefabricated slip surface at the last load showed the accuracy of the experimental model.

Generally, EPC would not be used for monitoring shear stress in practice, and EPCs were only arranged in vertical and horizontal directions in this experiment, so the variations of shear stresses were not discussed. In this test, the soils slid along the specific cambered surface, and the thickness of the soil mass was relatively large. Slopes with 
TABLE 4: Reliability verification of measured stresses in the free zone.

\begin{tabular}{|c|c|c|c|c|c|c|c|c|c|}
\hline $\begin{array}{l}\text { Stress } \\
\text { type }\end{array}$ & No. of EPCs & W statistic & $P$ value & Accept/reject (A/R) W test & Std. dev. & Minimum & Mean & Maximum & $\begin{array}{c}\text { Fitting } \\
\text { precision }\end{array}$ \\
\hline \multirow{5}{*}{ Vertical } & $2-5$ & 0.9194 & 0.3140 & $\mathrm{~A}$ & 0.066 & 8.90 & 8.98 & 9.08 & 0.9965 \\
\hline & $3-5$ & 0.9272 & 0.3831 & $\mathrm{~A}$ & 0.315 & 12.07 & 12.39 & 12.89 & 0.9969 \\
\hline & $4-3$ & 0.9262 & 0.3736 & A & 0.418 & 19.32 & 19.74 & 20.39 & 0.9979 \\
\hline & $4-4$ & 0.9274 & 0.3848 & A & 0.712 & 13.42 & 14.14 & 15.25 & 0.9976 \\
\hline & $5-2$ & 0.9279 & 0.3898 & A & 0.563 & 20.45 & 21.02 & 21.90 & 0.9977 \\
\hline \multirow{5}{*}{ Horizontal } & $2-5$ & 0.9275 & 0.3861 & A & 0.490 & 2.54 & 3.04 & 3.81 & 0.9978 \\
\hline & $3-5$ & 0.9272 & 0.3831 & $\mathrm{~A}$ & 0.451 & 3.09 & 3.55 & 4.25 & 0.9981 \\
\hline & $4-3$ & 0.9269 & 0.3804 & A & 0.659 & 6.49 & 7.16 & 8.18 & 0.9985 \\
\hline & 4-4 & 0.9269 & 0.3801 & A & 0.437 & 4.47 & 4.91 & 5.59 & 0.9980 \\
\hline & $5-2$ & 0.9273 & 0.3840 & A & 0.490 & 8.66 & 9.16 & 9.92 & 0.9981 \\
\hline
\end{tabular}

different cambered surfaces and different soil thickness need more work.

5.2. Stress Transfer Efficiency and Limit Load. In this paper, the STE equations established by the measured results are simple and practical, which are helpful to quantify the stress transfer process through limited stress monitoring points. At the same time, the phenomenon that the VSTEs are more than $100 \%$ reflects the degree of stress redistribution to some extent: the higher VSTE means larger stress redistribution. From the loading zone to the free zone, VSTEs within the same elevation difference showed an increasing trend along the horizontal direction, while a decreasing trend was shown in the same zones. Contrasting with VSTEs, opposite trends occurred for HSTEs. The results implied that soils in the lower part (close to the slip surface) were apparently affected by stress transfer, while the effect of stress redistribution seemed more salient in the upper part.

Although there existed more than one characteristic point of slopes of stress curves in different zones, for example, $120 \mathrm{kN}$ for 1-4 and 3-3 in Figure 8(a), growth types of vertical stress and horizontal stress on both sides of $80 \mathrm{kN}$ and $60 \mathrm{kN}$, respectively, were different. Except monitoring point 1-2, horizontal stress growth decreased firstly and then increased. However, growth stages of vertical stresses inside slope existed some differences. Soils close to slope surface and shear outlet $(2-4,2-5,4-2$, and 4-3) showed two stages, while overall there were three stages in other soils.

As to the limit load of the horizontal stresses was lower than that of the vertical stresses, a possible explanation for this might be that the lateral stresses were smaller than the normal stresses during soil skeleton compression.

5.3. Geometry Partitioning. Under the same conditions, the stress state of the soil unit in this test was largely determined by the distances from the bearing plate, slope surface, and slip surface. Table 5 shows that when horizontal stresses transferred from the transfer zone to the free zone at the same elevation, HSTEs gradually decrease, and the greater the depths, the greater the differences in HSTEs. In addition, VSTEs of 2-5 to 4-3 and 3-5 to 5-2 are greater than those of 2-4 to $4-2$ and 3-4 to 5-1 (153.27\%), respectively. Therefore, the part with smaller HSTEs and greater VSTEs was defined as the free zone. As can be seen from Table 5 and above, generally, HSTEs of the measuring points at the same elevation in the soils had a progressive decrease law. From equation (2), HSTEs from $1-3$ to $1-4$, from $2-2$ to $2-3$, and from $3-2$ to $3-3$ were $18.48 \%, 126.46 \%$, and $133.17 \%$, respectively, which were different from the above-mentioned rule. In the $x$-axis direction, VSTEs were less than $100 \%$ on the left side of the $1600-1900 \mathrm{~mm}$ interval but greater than or even far greater than $100 \%$ on the right side. Accordingly, the 1600-1900 mm section was used as the dividing segment between the loading zone and the transfer zone.

The partitioning study of slope reinforcement and disposal and susceptibility to disaster and so forth, caused by the change of stress field, is also one of the key problems to the rational and safe construction of slope engineering. The previous zonation studies on the susceptibility [24] and stability [25] of rocks and soils were carried out by means of numerical simulation or combining monitoring and investigation in situ. The geometry partitioning method adopted in this paper via STEs is simpler and more intuitive.

It should be pointed out that there is no consistent mode for the divisions of the loading zone, the transfer zone, and the free zone, depending on the load form and its position, slope geometry, soil uniformity, and so forth. The quantity of EPCs in this test was relatively small, and the strict boundaries between the various regions of the soils are not available.

5.4. Stress Redistribution. With the increase of depths, the vertical stress isolines caused by the gravity of soils would deflect to a greater degree in the vicinity of the shear outlet in the free zone but incline to small degree in the loading zone and in the transfer zone. Due to the small changes of vertical stresses near the slope surface, in this paper, the error caused by the assumption that the initial vertical stress isolines were approximately parallel to the slope crest was small. Figures 11 and 12 are typical stress contours during loading.

As shown in Figure 11, the isolines of vertical stresses in test soils were still approximately parallel to the slope crest in the initial loading stages, and then the isolines in the loading 


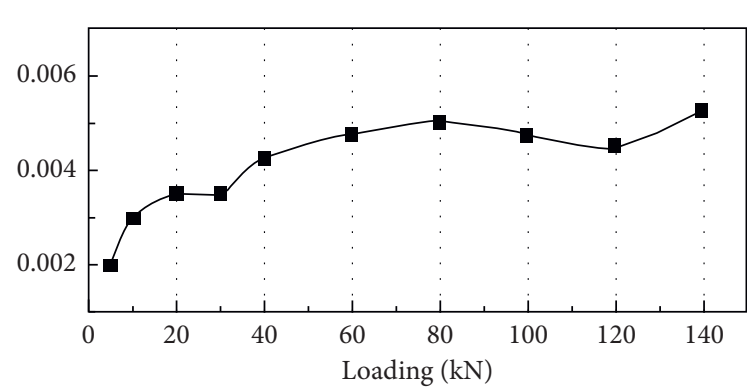

$\rightarrow-1-4$

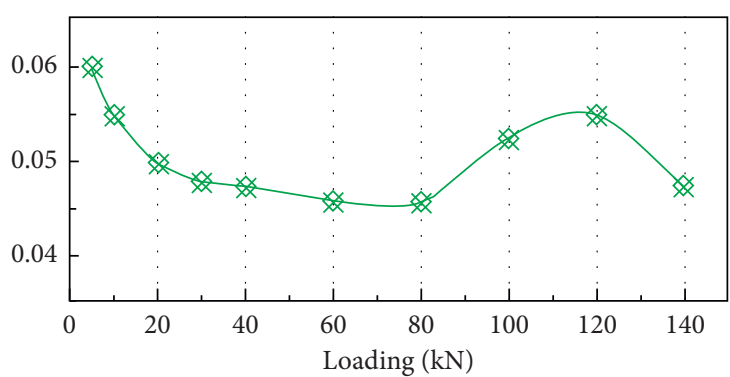

- 3-3

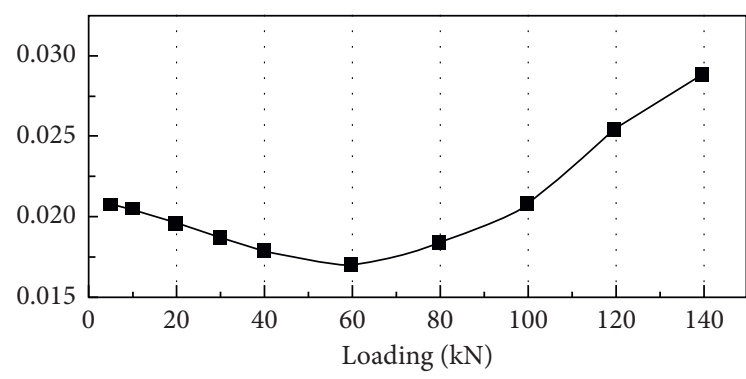

$-1-4$

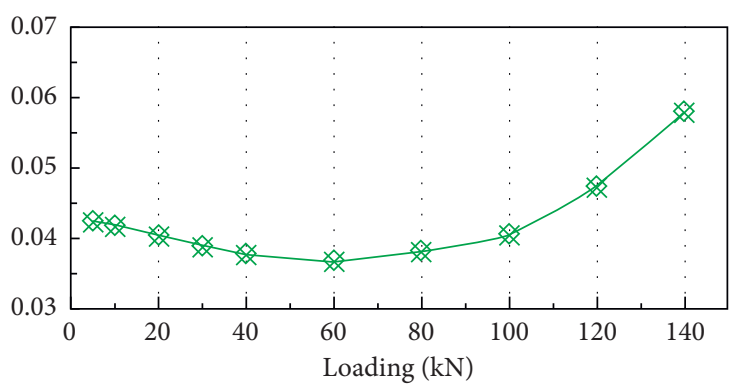

- 3-3

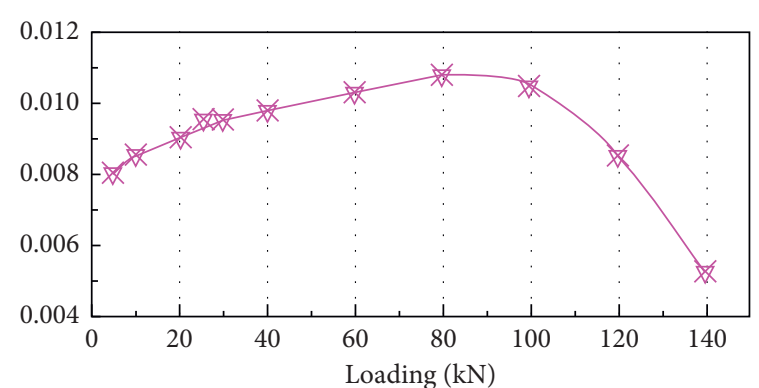

$\times 2-4$

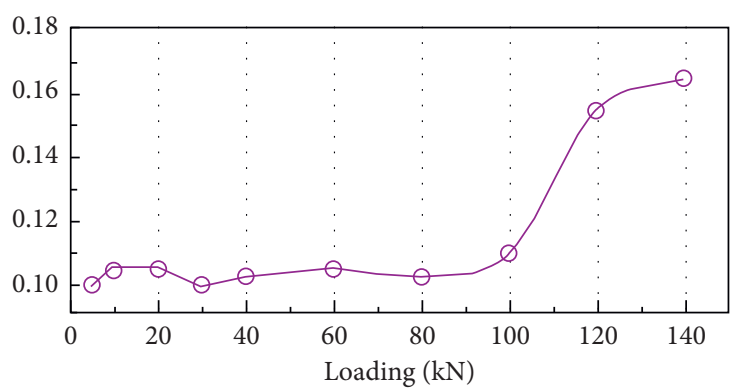

- $4-2$

(a)

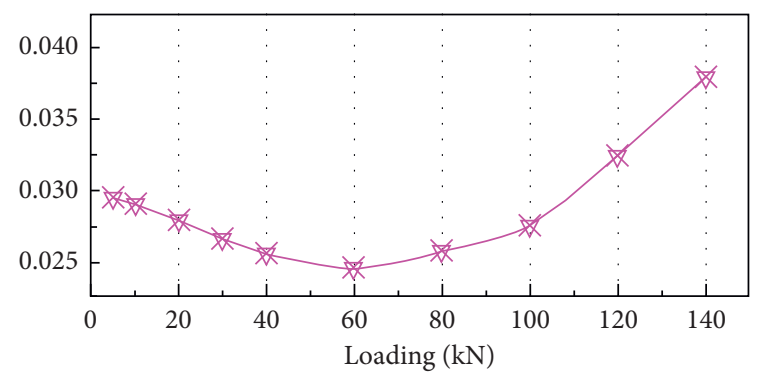

$\rightarrow 2-4$

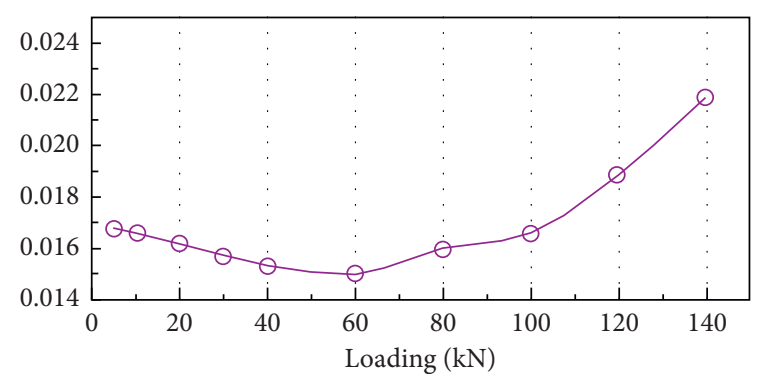

$-4-2$

(b)

FiguRE 8: Slopes of stress curves in the transfer zone (take monitoring points 1-4, 3-3, 2-4, and 4-2 as an example). (a) Vertical and (b) horizontal.

zone gradually tended to deflect to the vertical direction in the following loading stages. The isolines in the transfer zone gradually deflected toward the slip surface during loading, while deflecting amplitude of isolines in the free zone had little change. The above-mentioned stress variation amplitude and downtrend of VSTEs in depth were in conformity with the variations of isolines reflected in the contours. The occurrence that VSTEs were more than 100\% in the transfer zone and in the free zone was saliently affected by stress redistribution.

From Figure 12, we have the following: (1) During the loading process, isolines under the bearing plate gradually diffused in the horizontal direction. Namely, the effect of surcharge load on the horizontal stresses was the most 


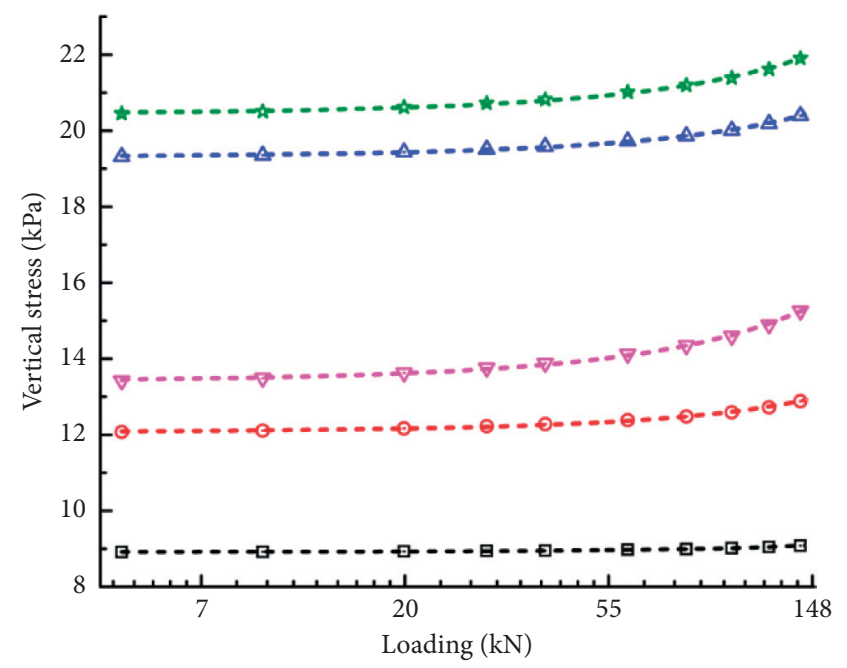

$\bullet \quad 2-5$
$\odot \quad 3-5$
$\triangle \quad 4-3$

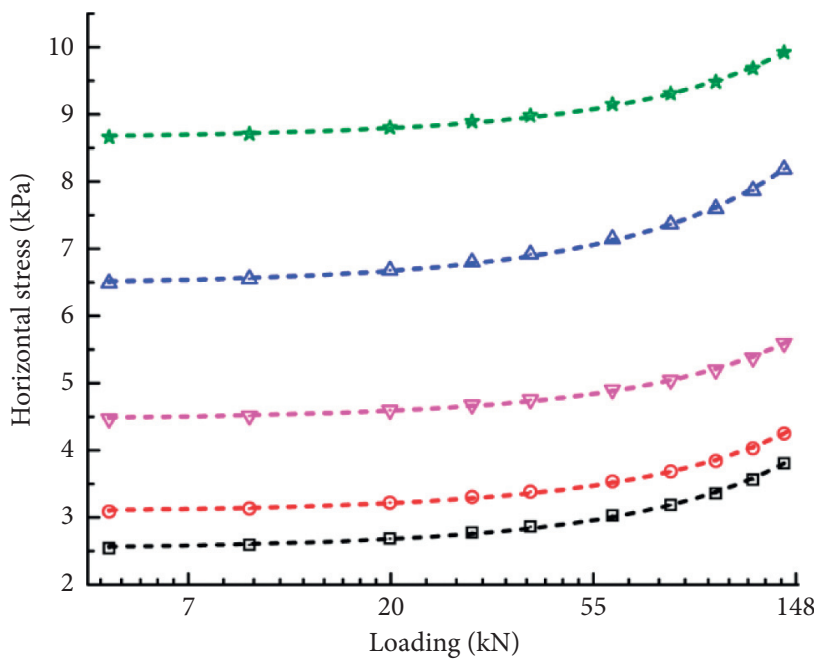
๑ $2-5$
○ $3-5$
is $5-2$

$\triangle 4-3$

(b)

FIGURE 9: Relationship between the qualified stresses and loading in the free zone. (a) Vertical stress. (b) Horizontal stress.

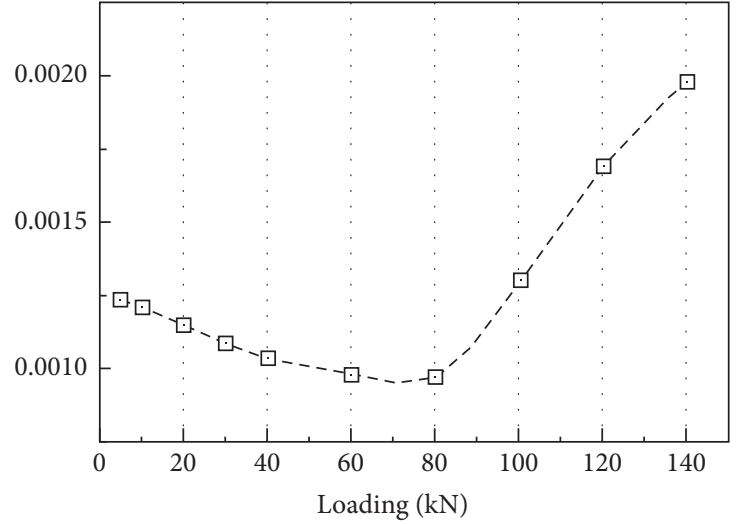

$-\square-2-5$ vertical

(a)

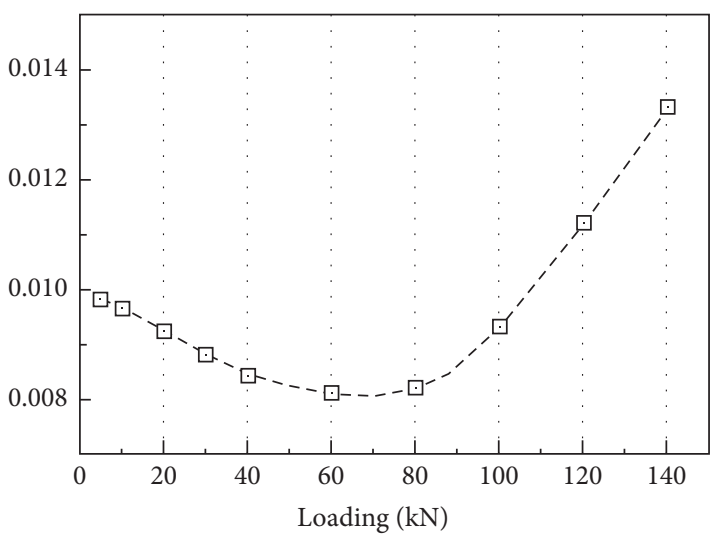

$-\square-2-5$ horizontal

(c)

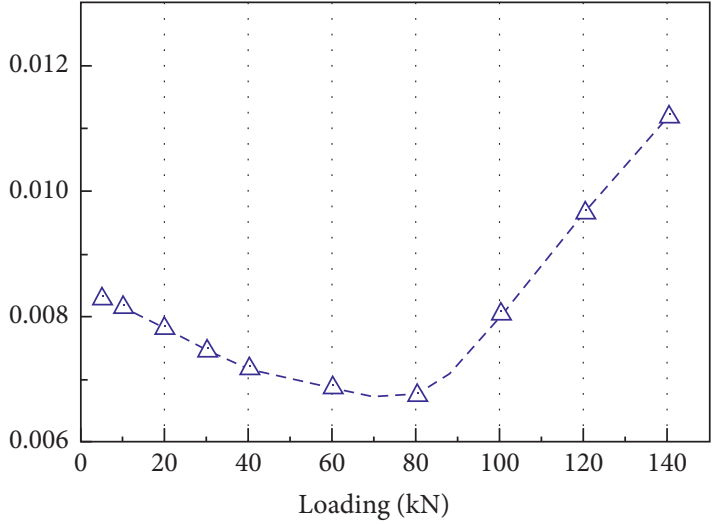

$-\Delta-4-3$ vertical

(b)

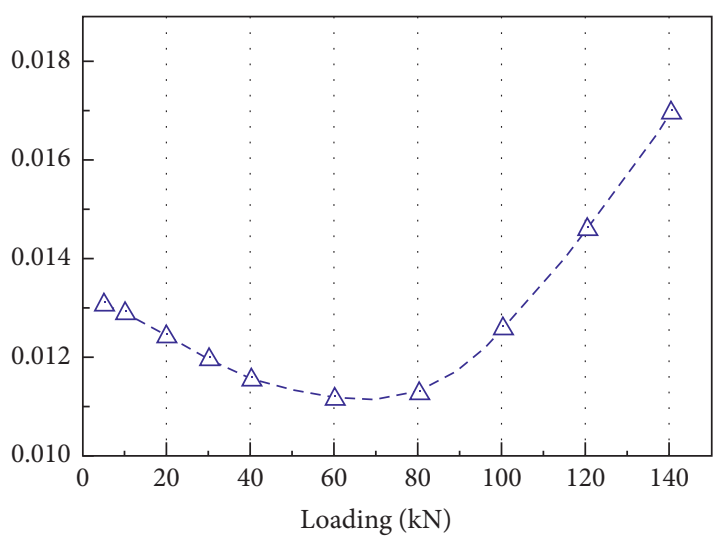

- $\Delta-4-3$ horizontal

(d)

FIgURE 10: Slopes of stress curves in the free zone (take monitoring points 2-5 and 4-3 as an example). 


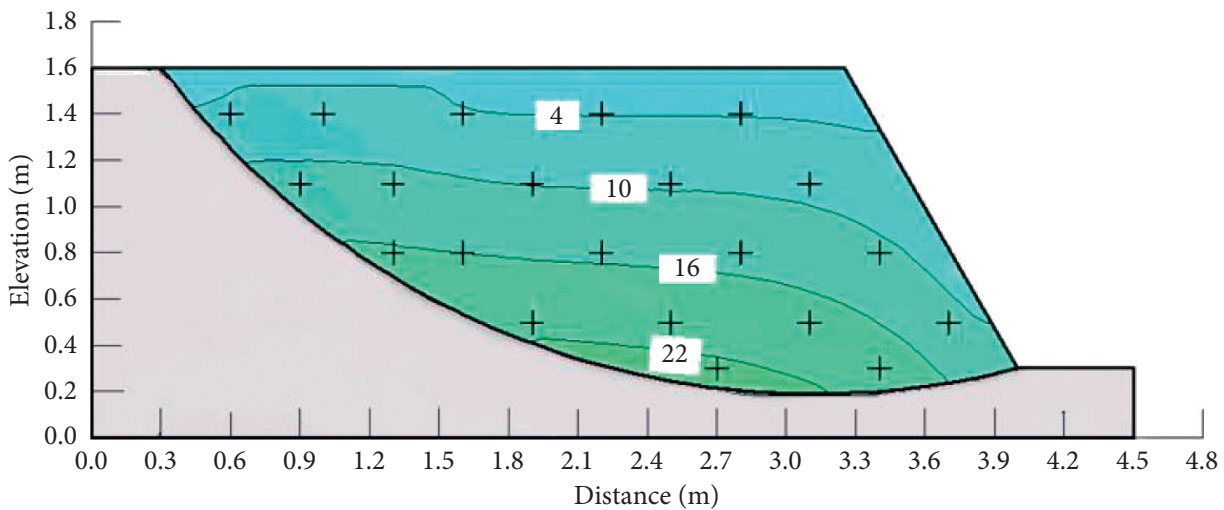

(a)

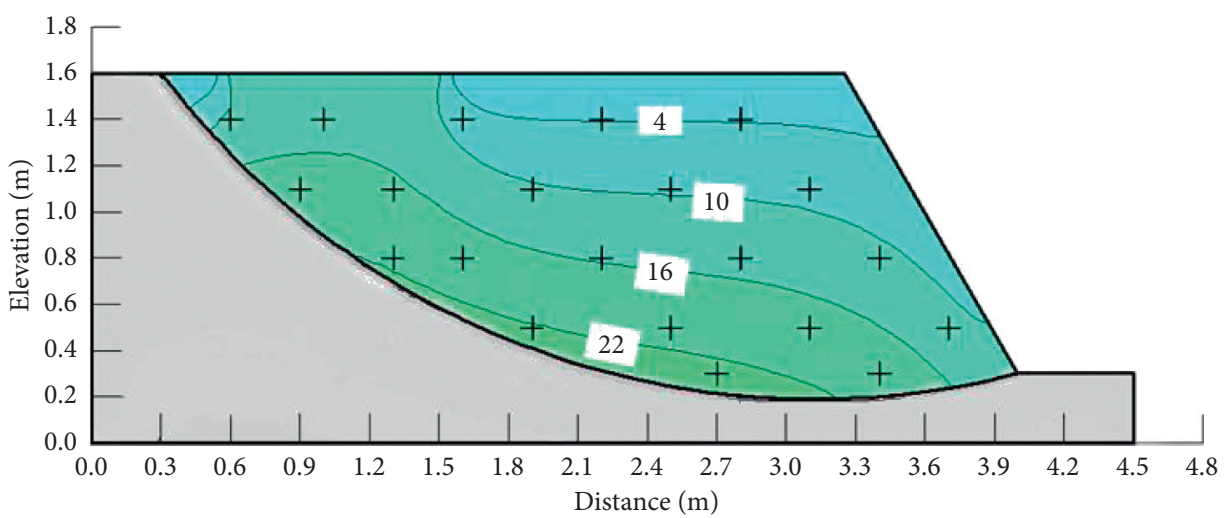

(b)

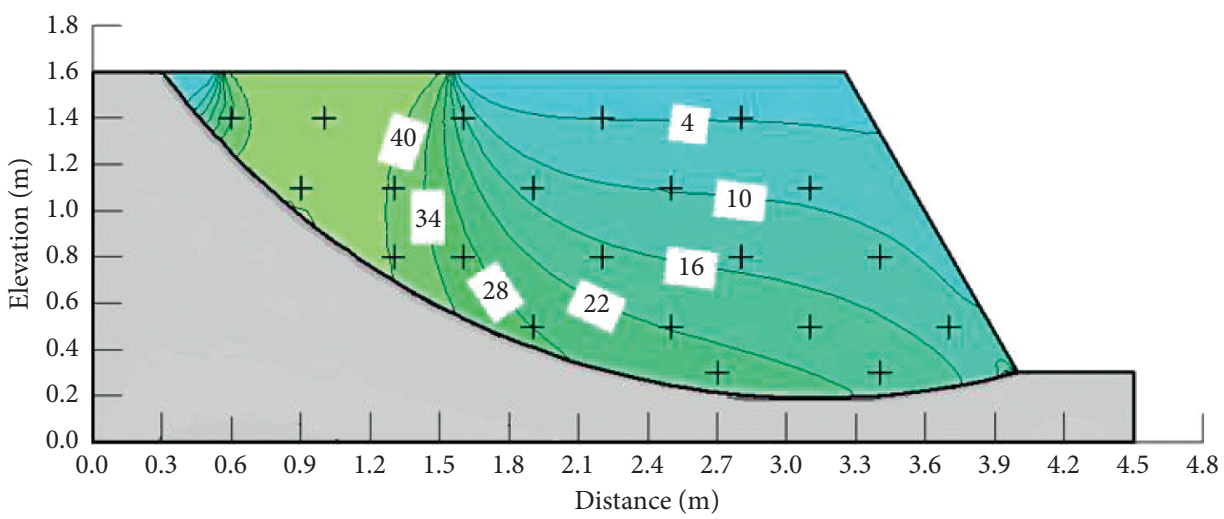

(c)

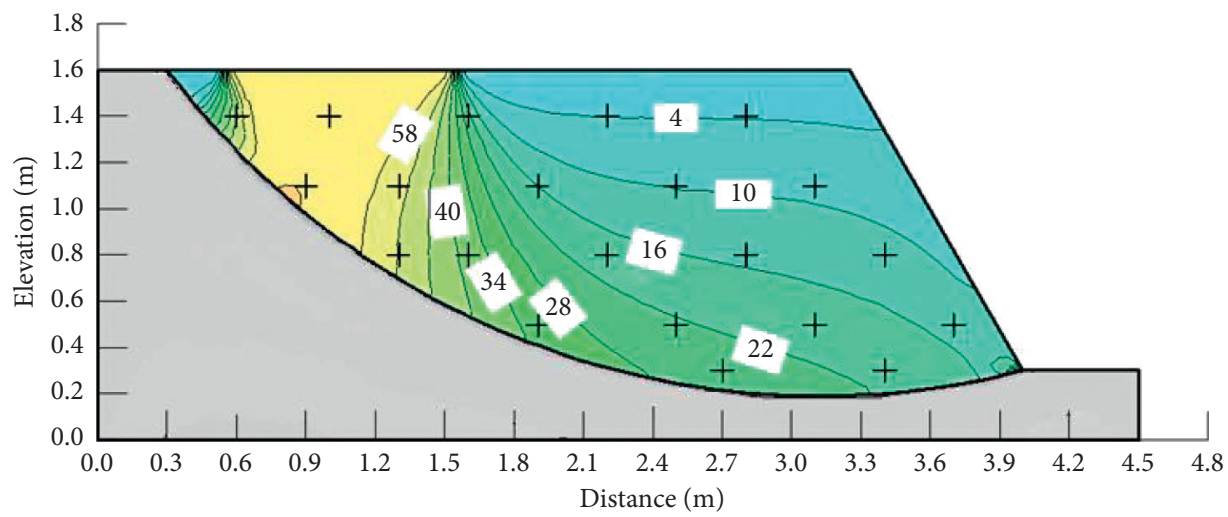

(d)

Figure 11: Typical vertical stress contours during loading process (unit of isoline label: $\mathrm{kPa}$ ). Loading to (a) $5 \mathrm{kN}$, (b) $20 \mathrm{kN}$, (c) $80 \mathrm{kN}$, and (d) $120 \mathrm{kN}$. 


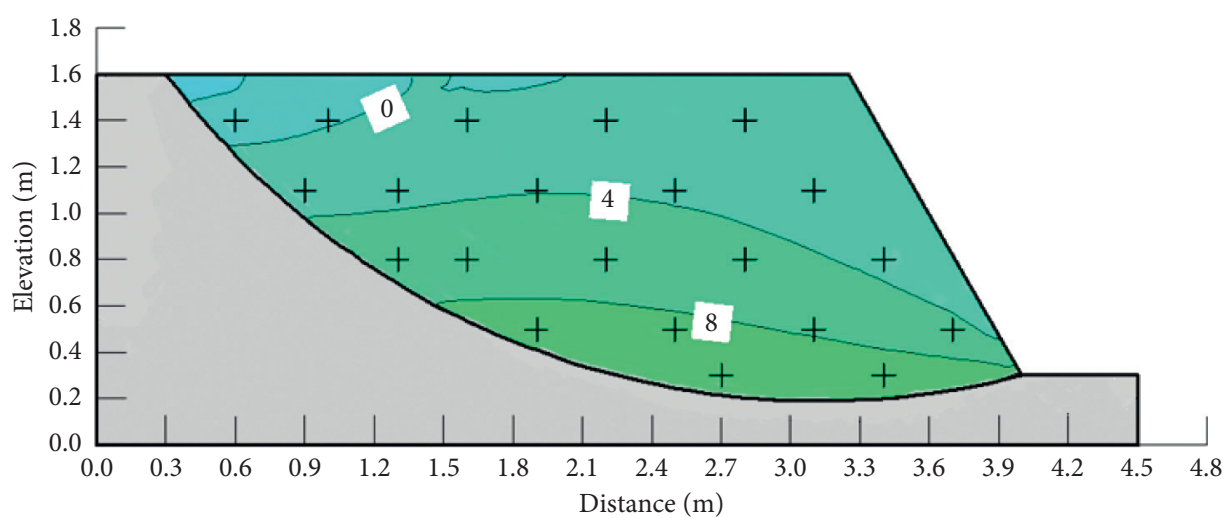

(a)

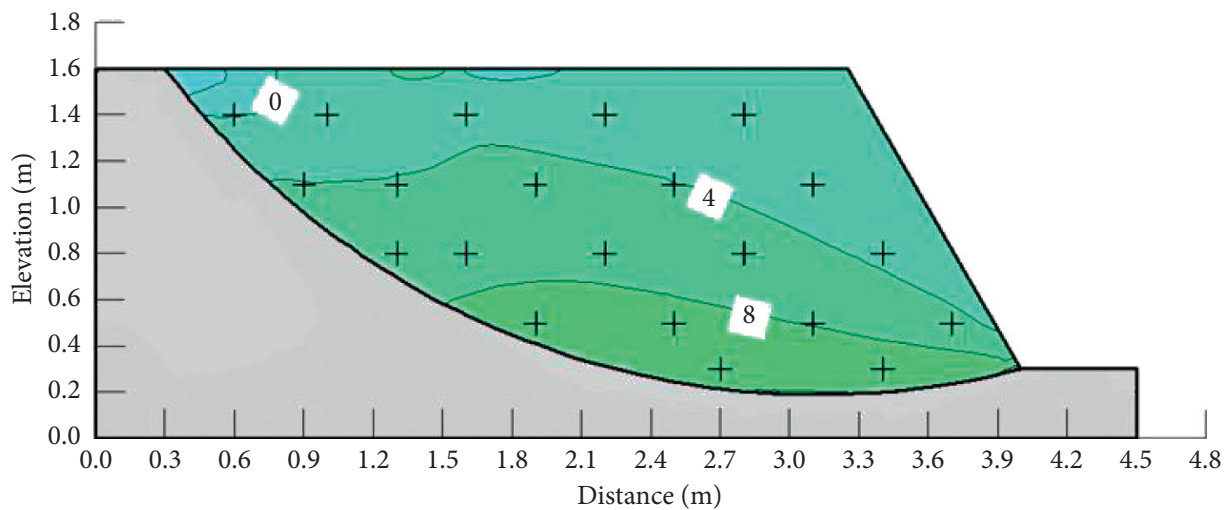

(b)

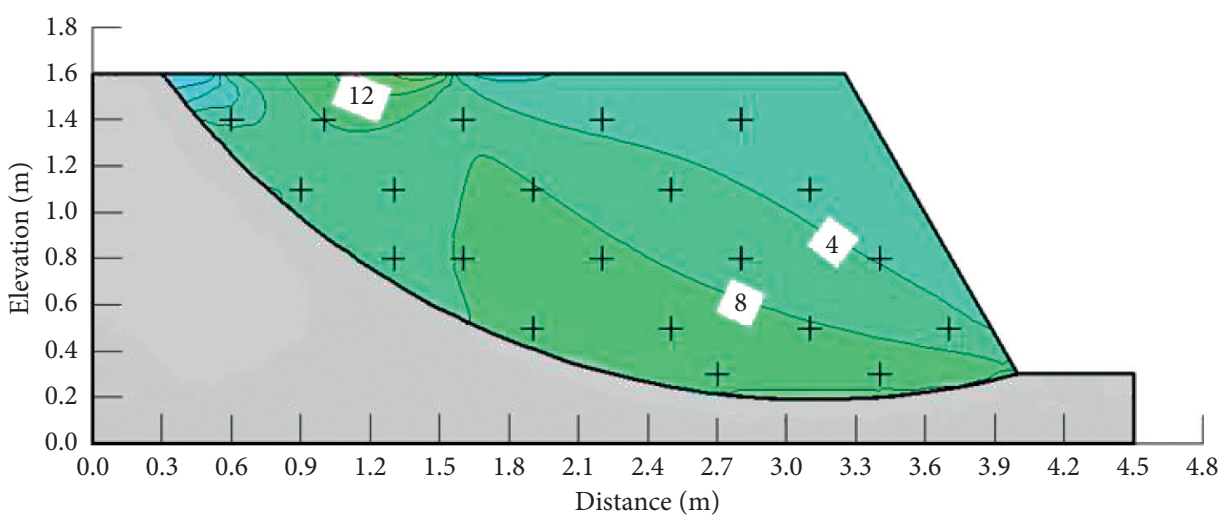

(c)

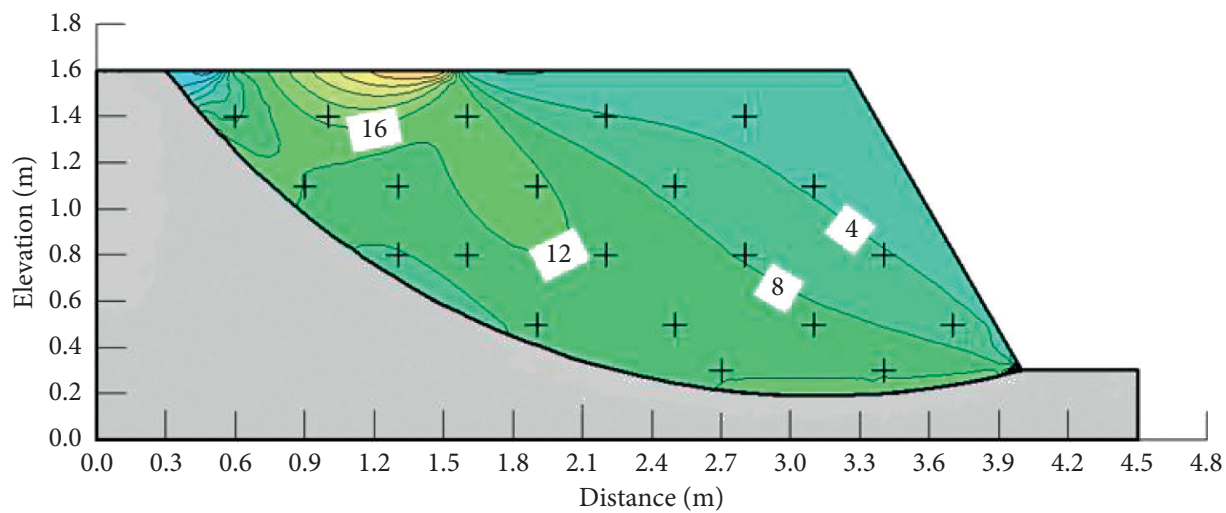

(d)

FIGURE 12: Typical horizontal stress contours during loading process (unit of isoline label: $\mathrm{kPa}$ ). Loading to (a) $5 \mathrm{kN}$, (b) $20 \mathrm{kN}$, (c) $60 \mathrm{kN}$, and (d) $120 \mathrm{kN}$. 
TABLE 5: HSTEs in the transfer zone and in the free zone.

\begin{tabular}{lcc}
\hline Transfer direction & Transfer efficiency (\%) & Difference value (\%) \\
\hline $2-3$ to $2-4$ & 38.46 & 4.59 \\
$2-4$ to $2-5$ & 33.87 & \\
$3-3$ to $3-4$ & 50.00 & 8.12 \\
$3-4$ to $3-5$ & 41.88 & \\
$4-2$ to $4-3$ & 75.78 & 9.51 \\
$4-3$ to $4-4$ & 66.27 & \\
\hline
\end{tabular}

significant in the loading zone, while it gradually weakened in the transfer zone and in the free zone. These were consistent with the gradual decrease of the HSTEs at the same elevation from the transfer zone to the free zone and the aforementioned horizontal stress variation amplitude. (2) The nearer to the bearing plate in the loading zone, the greater the horizontal stresses, which was in line with the decrease of HSTEs with increasing depths. The horizontal stress isolines gradually extended to the slip surface in the transfer zone and in the free zone, which was in accordance with the increase of HSTEs with depth.

\section{Conclusions and Suggestions}

In this paper, a large-scale clay landslide model experiment with prefabricated cambered slip surface was constructed. EPCs were embedded into slip mass to monitor the changes of vertical and horizontal stresses under set load sequence. Based on stress monitoring data, VSTE and HSTE indicators were established to quantify stress transfer process. Deflection of stress isolines derived from numerical simulation was also employed to describe stress redistribution. The main conclusions and suggestions are as follows:

(1) The limit loads of vertical and horizontal stresses increase were $80 \mathrm{kN}$ and $60 \mathrm{kN}$, respectively. The closer to surcharge load location, the greater variations of vertical and horizontal stresses. Inside the slope, horizontal stress growth has two stages; vertical stress growth has two stages in soils close to slope surface and shear outlet, while there are three stages in other soils.

(2) Stress transfer always accompanies stress redistribution. The higher VSTE means larger stress redistribution. Soils in the lower part (close to the slip surface) were apparently affected by stress transfer, while the effect of stress redistribution was more salient in the upper part.

(3) VSTEs and HSTEs showed different trends in soil slope. Deflecting amplitude of stress isolines computed by numerical simulation was consistent with results revealed by STEs, and VSTE and HSTE indicators are recommended for quantifying stress transfer and redistribution.

(4) VSTE $<100 \%$ is the key feature of the loading zone that distinguishes it from the transfer zone and the free zone. Geometry partitioning conducted by STEs could reflect stress variation characteristics in different zones.

\section{Data Availability}

The data used to support the findings of this study are available from the corresponding author upon request.

\section{Conflicts of Interest}

The authors declare no conflicts of interest regarding the publication of this paper.

\section{Acknowledgments}

The authors would like to acknowlege Projects 51478066 and 51178488 supported by the National Natural Science Foundation of China. The authors greatly thank Associate Professors Bao-Yun Zhao, Tong-Qing Wu, and Zi-Yun Li from the School of Civil Engineering and Architecture, Chongqing University of Science \& Technology, and ZhenYang Feng, Ph.D., Yong Zheng, M.D., and Hong-Lin Liu, M.D., from the School of Civil Engineering of Chongqing University for their help during the experiment.

\section{References}

[1] A. O. Oliva González, D. M. Jiménez, I. N. Alvarez Garcia, C. G. Nicieza, and A. E. Álvarez Vigil, "Hillside instability in the Tijuana metropolitan area. Analysis of landslide-provoked building collapse," Engineering Failure Analysis, vol. 46, pp. 166-178, 2014.

[2] A. M. Puzrin, E. E. Alonso, and N. M. Pinyol, Geomechanics of Failures, Springer Science, Dordrecht, The Netherlands, 2010.

[3] H.-Z. Wei, D.-S. Xu, and Q.-S. Meng, "A newly designed fiberoptic based earth pressure transducer with adjustable measurement range," Sensors, vol. 18, no. 4, p. 932, 2018.

[4] K. Atakan and A. Ojeda, "Stress transfer in the Storegga area, offshore mid-Norway," Marine and Petroleum Geology, vol. 22, no. 1-2, pp. 161-170, 2005.

[5] P. Jeanne, J. Rutqvist, P. F. Dobson, M. Walters, C. Hartline, and J. Garcia, "The impacts of mechanical stress transfers caused by hydromechanical and thermal processes on fault stability during hydraulic stimulation in a deep geothermal reservoir," International Journal of Rock Mechanics and Mining Sciences, vol. 72, pp. 149-163, 2014.

[6] P. Yazdi, M. A. Santoyo, and J. M. Gaspar-Escribano, "Analysis of the 2012 Ahar-Varzeghan (Iran) seismic sequence: insights from statistical and stress transfer modeling," Global and Planetary Change, vol. 161, pp. 121-131, 2018.

[7] Y. Lv, H. Liu, C. W. W. Ng, X. Ding, and A. Gunawan, "Three-dimensional numerical analysis of the stress transfer mechanism of XCC piled raft foundation," Computers and Geotechnics, vol. 55, pp. 365-377, 2014.

[8] C.-P. Lu, Y. Liu, G.-J. Liu, and T.-B. Zhao, "Stress evolution caused by hard roof fracturing and associated multi-parameter precursors," Tunnelling and Underground Space Technology, vol. 84, pp. 295-305, 2019.

[9] G. W. Jia, T. L. T. Zhan, Y. M. Chen, and D. G. Fredlund, "Performance of a large-scale slope model subjected to rising and lowering water levels," Engineering Geology, vol. 106, no. 1-2, pp. 92-103, 2009. 
[10] A. K. Leung and C. W. W. Ng, "Field investigation of deformation characteristics and stress mobilisation of a soil slope," Landslides, vol. 13, no. 2, pp. 229-240, 2016.

[11] J. Ma, H. Tang, X. Hu, A. Bobet, R. Yong, and M. A. M. Ez Eldin, "Model testing of the spatial-temporal evolution of a landslide failure," Bulletin of Engineering Geology and the Environment, vol. 76, no. 1, pp. 323-339, 2017.

[12] G. Chen, X. Meng, L. Qiao, Y. Zhang, and S. Wang, "Response of a loess landslide to rainfall: observations from a field artificial rainfall experiment in Bailong River Basin, China," Landslides, vol. 15, no. 5, pp. 895-911, 2018.

[13] M. Lamandé and P. Schjønning, "Transmission of vertical stress in a real soil profile. Part II: effect of tyre size, inflation pressure and wheel load," Soil and Tillage Research, vol. 114, no. 2, pp. 71-77, 2011.

[14] P. Schjønning, M. Stettler, T. Keller, P. Lassen, and M. Lamandé, "Predicted tyre-soil interface area and vertical stress distribution based on loading characteristics," Soil and Tillage Research, vol. 152, pp. 52-66, 2015.

[15] C.-N. Liu and C.-C. Wu, "Integrating GIS and stress transfer mechanism in mapping rainfall-triggered landslide susceptibility," Engineering Geology, vol. 101, no. 1-2, pp. 60-74, 2008.

[16] C. W. W. Ng, L. T. Zhan, C. G. Bao, D. G. Fredlund, and B. W. Gong, "Performance of an unsaturated expansive soil slope subjected to artificial rainfall infiltration," Géotechnique, vol. 53, no. 2, pp. 143-157, 2003.

[17] K. Ishihara and I. Towhata, "Sand response to cyclic rotation of principal stress directions as induced by wave loads," Soils and Foundations, vol. 23, no. 4, pp. 11-26, 1983.

[18] H. Lin and D. Penumadu, "Experimental investigation on principal stress rotation in Kaolin clay," Journal of Geotechnical and Geoenvironmental Engineering, vol. 131, no. 5, pp. 633-642, 2005.

[19] Z. X. Yang, X. S. Li, and J. Yang, "Undrained anisotropy and rotational shear in granular soil," Géotechnique, vol. 57, no. 4, pp. 371-384, 2007.

[20] X. Xiong, B. Shan, Y. Zheng, and R. Wang, "Stress transfer and its implication for earthquake hazard on the Kunlun Fault, Tibet," Tectonophysics, vol. 482, no. 1-4, pp. 216-225, 2010.

[21] R. M. Iverson, "Scaling and design of landslide and debrisflow experiments," Geomorphology, vol. 244, pp. 9-20, 2015.

[22] Z.-W. Zhu, B. Liu, P. Liu, B.-Y. Zhao, and Z.-Y. Feng, "Model experimental study of landslides based on combined optical fiber transducer and different types of boreholes," Catena, vol. 155, pp. 30-40, 2017.

[23] M. Beer, Y. Zhang, S. T. Quek, and K. K. Phoon, "Reliability analysis with scarce information: comparing alternative approaches in a geotechnical engineering context," Structural Safety, vol. 41, pp. 1-10, 2013.

[24] L. Cascini, "Applicability of landslide susceptibility and hazard zoning at different scales," Engineering Geology, vol. 102, no. 3-4, pp. 164-177, 2008.

[25] C. Zhang, H. Zhou, and X. Feng, "Stability assessment of rockmass engineering based on failure approach index," Yantu Lixue/Rock and Soil Mechanics, vol. 28, no. 5, pp. 888-894, 2007, in Chinese. 